\title{
Variant pronator teres muscle and supracondylar process: interesting for anatomists and surgeons but a well-known variation
}

\author{
Georgi P. Georgiev ${ }^{1}$ (D) $\cdot$ R. Shane Tubbs ${ }^{2,3}$
}

Received: 1 February 2020 / Accepted: 14 February 2020 / Published online: 26 February 2020

○) Springer-Verlag France SAS, part of Springer Nature 2020

We read with interest the article by Narayanan and Adikesavan [5] on three unique variations- - "Coexistence of variant pronator teres muscle and variant course of the neurovascular structures in the arm: clinical significance." We appreciate the authors for describing their interesting case report with three unique anatomical variations: (1) a variant origin of pronator teres (PT) from the supracondylar process (SP); (2) a variant course of the brachial neurovascular bundle behind the SP; (3) a proximal origin of the radial artery from the brachial artery. According to these authors, knowledge on such variations will be of benefit to surgeons during their practice, as well as to radiologist in interpretation of, for example, angiograms.

However, we do not agree with the author's claims that the following are unique: (1) first, the unique origin of PT from the SP. We would like to point out that this variation was described four centuries ago in the works of Macalister [4] and has been mentioned more recently [1-3]; (2) second, according to the authors, the variant course of the brachial neurovascular bundle was behind the SP. The variation also is widely known, e.g., Bergman et al. [1]-Illustrated Encyclopedia of Human Anatomic Variation; and third, (3) the proximal origin of the radial artery from the brachial artery. This is also a well-known variation described in the previously mentioned resource [1], as well as in classical anatomical and surgical textbooks.

In conclusion, this case highlights that before accepting some variations as unique, it is necessary for authors to

Georgi P. Georgiev

georgievgp@yahoo.com

1 Department of Orthopedics and Traumatology, University

Hospital Queen Giovanna-ISUL, Medical University

of Sofia, 8 Bialo More Str., BG 1527 Sofia, Bulgaria

2 Department of Anatomy, St. George's University, St. George's, Grenada

3 Department of Neurosurgery, Tulane University School of Medicine, New Orleans, LA, USA explore old anatomical textbooks and perform an extensive review of current literature. These steps will avoid future miscommunications.

\section{References}

1. Bergman RA, Afifi AK, Miyauchi R (2017) Title of subordinate document. In: Illustrated encyclopedia of human anatomic variations. Available via DIALOG. https://www.anatomyatlases.org/ AnatomicVariants/MuscularSystem/Text/E/25Extensor.shtml. Accessed 15 Jan 2020

2. Jelev L, Georgiev GP (2009) Unusual high-origin of the pronator teres muscle from a Struthers' ligament coexisting with a variation of the musculocutaneous nerve. Rom J Morphol Embryol 50:497-499

3. Loukas M, Pennell C, Tubbs RS, Cohen-Gadol AA (2010) Sir John Struthers (1823-1899) and his ligament and arcade. Neurosurgery 66:1170-1173. https://doi.org/10.1227/01.NEU.00003 69197.08381.BE

4. Macalister A (1875) Additional observations on muscular anomalies in human anatomy (third series), with a catalogue of the principal muscular variations hitherto published. Trans Roy Irish Acad 25:1-130

5. Narayanan S, Adikesavan PN (2020) Coexistence of variant pronator teres muscle and variant course of the neurovascular structures in the arm: clinical significance. Surg Radiol Anat. https://doi. org/10.1007/s00276-019-02413-6

Publisher's Note Springer Nature remains neutral with regard to jurisdictional claims in published maps and institutional affiliations. 